\title{
RELATIONAL DATABASE SYSTEMS SUPPORT FOR Products DeVElopment Process at THE ENTERPRISE LEVEL USING OPEN SOURCE SOFTWARE
}

\author{
Rosu, S.M.; DragoI, G.; GuRAN, M. \& Rosu, L.
}

Abstract: Open source software with free sources is a good option these products having a remarkable quality because of fact then often these projects get together distinguished programmers and everything is public, open and anybody can come. Very well it's than management team to know from the beginning what are the costs (human and material) and how much will be during the project. Generally, to realize and to implement a database project are requisite a period within few months and few years. Certainly, in the actual market the price makes the rules. Enterprise software solution is influence by shrift, medium or long-term calculation. Decision can be take consequence a comparative analysis.

Key words: enterprise, relational database, middleware, open souce software, client server architecture.
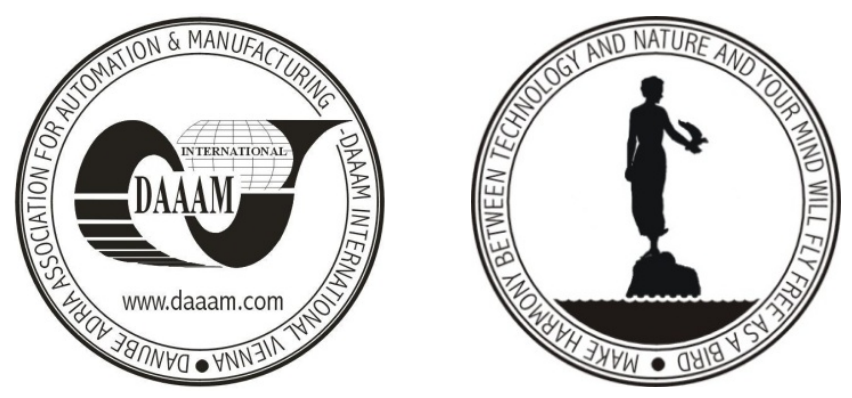

Authors' data: PhD. Student Rosu, S[ebastian] M[arius]*; Prof. Dragoi, G[eorge]**; Prof. Guran, M[arius] ${ }^{* *}$; M.Sc. Rosu, L[uminita]**, *Special Telecommunications Service, Bld. Unirii, Bl. 37A, Et. 1, Ap. 7, 120237, Buzau, RO, ** University Politehnica of Bucharest, ILS Department, UPB-PREMINV Research Centre, 313, Splaiul Independentei, Sector 6, 060042, Bucharest, RO, gdragoi@mix.mmi.pub.ro, luminita@romet.ro,mguran@mix.mmi.pub.ro, sebastianrosu@stsnet.ro

This Publication has to be referred as: Rosu, S[ebastian] M[arius]; Dragoi, G[eorge]; Guran, M[arius] \& Rosu, L[uminita] (2008). Relational Database Systems Support for Products Development Process at the Enterprise Level Using Open Source Software, Chapter 58 in DAAAM International Scientific Book 2008, pp. 685-696, B. Katalinic (Ed.), Published by DAAAM International, ISBN 978-3901509-66-7, ISSN 1726-9687, Vienna, Austria

DOI: $10.2507 /$ daaam.scibook.2008.58 